SECTION 21. Pedagogy. Psychology. Innovations in the field of education.

Alpys Abdeshovich Papishev

doctor of pedagogical Sciences, associate Professor of the Department of higher mathematics

L.N.Gumilyov Eurasian National university, Kazakhstan

Darap57@mail.ru

\title{
PSYCHOLOGICAL, PEDAGOGICAL AND METHODOLOGICAL LITERATURE ON PROFESSIONAL AND MEANINGFUL QUALITIES OF A TEACHER OF MATHEMATICS
}

\begin{abstract}
The article gives a short analysis of psychological, pedagogical and methodological literature about professional and meaningful qualities of a teacher of mathematics.
\end{abstract}

Key words: psychology, psychological and pedagogical approach, a teacher, mathematics.

\section{ПСИХОЛОГО-ПЕДАГОГИЧЕСКАЯ, МЕТОДИЧЕСКАЯ ЛИТЕРАТУРА О ПРОФЕССИОНАЛЬНО ЗНАЧИМЫХ КАЧЕСТВАХ УЧИТЕЛЯ МАТЕМАТИКИ}

\begin{abstract}
Аннотация: В статье приводится краткий анализ психологической, педагогической и методологической литературы о профессиональных $и$ значащих качествах учителя математики.
\end{abstract}

Ключевые слова: психология, психологические и педагогические методы, учитель, математика.

Подготовка будущего учителя математики заслуживает пристального внимания и изучения. Так, при организации этого процесса в стенах педагогического вуза необходимо четко определить чему и как следует обучать будущего педагога, чтобы он как можно быстрее достиг успеха в своей педагогической деятельности. В настоящее время при обсуждении этого вопроса часто сталкиваются две противоположные позиции:

1. Нужно дать хорошее математическое образование, и это основное;

2. Необходимо дать хорошую общепедагогическую и методологическую подготовку, и это самое главное.

В действительности, по мнению академика Б.В. Гнезденко [1], и та, и другая позиции односторонние, поскольку в подготовке учителя математики нужна и та, и другая.

Недооценка первого положения приводит к тому, что авторитет учителя математики, как, впрочем, и учителя по любому другому предмету, будет безнадёжно подорван, когда учащиеся обнаружат, что знание их учителя лишь ненамного отличается от того, что они сами должны усвоить. И здесь не помогут не знания истории педагогики, ни знания частных методик. В то же время как можно добиться успеха даже при хорошем знании предмета, если учитель не имеет подхода к ученикам, не может ясно и убедительно изложить суть предмета, не может довести основные понятия и метода до полного понимания, увязав теоретические сведения с возможным практическим применениям знаний.

Математическое образование будущего учителя математики не может быть построено по той же схеме, что и математическое образование математика-исследователя или математика-программиста. Если от математика- исследователя требуется, помимо широкого математического образования, глубокое проникновение в какой-нибудь узкий её раздел, то от математика- учителя требуется нечто иное. Прежде всего, он должен 
представлять себе структуру современной математики в целом, связь математики с другими науками и её практические применения. От учителя математики требуется не только хорошее знание предмета, но и умение увлечь им учащихся, вызвать у них потребность своевременно готовиться к каждому уроку, вникать в суть понятий, добиваться в первую очередь понимания и только после этого запоминания.

Б.В. Гнеденко указывает те же качества, которые, по его мнению, нужно развивать, чтобы стать хорошим учителем математики: любить свое дело и быть им увлеченным, верить в исключительную общественную ценность, знать свой предмет, его историю и философские проблемы; уметь излагать свой предмет увлеченно и интересно; с уважением относиться к учащимся; учитель математики, в сотый раз доказывая некоторую теорему, должен переживать радость открытия и передавать эту радость учащимся; видеть связь математики с практикой и уметь об этом рассказывать вовремя, кратко и убедительно; систематически следить за развитием науки; не подавлять инициативу учащихся, а направлять её; уметь анализировать свои поступки, педагогические удачи и неудачи и тем самым обогащать свой опыт.

Всё это очень ценные соображения, но многие из них, из этих рекомендаций, имеют общее значение, имеют отношение не только к подготовке учителя математики, но и учителей любой другой специальности.

Несомненный интерес для начинающего учителя математики представляют советы известного советского методиста-математика В.М. Брадиса о том, как избежать ошибки в своей деятельности, какие требования к личности учителя математики предъявляет его педагогический труд [2]. Прежде всего, В.М. Брадис обращает внимание молодого учителя математики на недопустимость подавления инициативы учащихся. Любое самостоятельное решение задачи надо всегда приветствовать, отличать его достоинства, выяснять его недостатки, сравнивать с другими возможными решениями той же задачи. Даже более того: нужно самым внимательным образом относиться и к ошибочным решениям, всемерно поощряя инициативу учащихся, но ясно показывая, чем это решение неудачно. Правильное решение одно задачи, к которому класс пришел, разобрав и отвергнув одно-два неправильных, выдвинутых самими учениками, приносит во много раз больше пользы, чем ознакомление с готовыми решениями нескольких задач, предложенных учителем.

Все разговоры о том, что математика по своему существу «сухой предмет», настолько не интересный, что заниматься им можно только по принуждению, является исключительно плодом ошибок, допущенных учителем или по неведению, или из-за небрежности. Для того, чтобы урок математики мог вызвать у учащихся интерес, учителю мало держать в памяти обширные сведения из истории науки, их необходимо усвоить творчески. Об этом прекрасно было сказано А.Н. Колмогоровым. От преподавателя в средней школе требуется не только твердое знание преподаваемой науки. Хорошо преподавать математику может только тот человек, который сам ею увлечен и воспринимает её как живую, развивающуюся науку. Вероятно, многие учащиеся средней школы знают, насколько увлекательной, а благодаря этому легкой и доступной становится математика у таких учителей $[3$, с.3].

B.M. Брадис считает, что нельзя с успехом учить математике, не интересуясь её связью с другими школьными дисциплинами, с практикой. Надо знать, какого рода запросы к математическим знаниям и умениям предъявляют физика, астрономия, черчение и принимать меры к тому, чтобы ученики могли свободно использовать свои математические знания при изучении этих предметов.

Таким образом, в своей практической работе с учащимися поставленной цели математического образования успешно достигает каждый учитель, обладающий высокой математической культурой, умеющий развивать интерес учащихся к математике. Однако, для будущего учителя математики, по мнению известного советского ученого, методистаматематика Р.С. Черкасова [4], важно, овладевая основами своей будущей профессии, 
дополнять хорошее знание математики, педагогических и общественных дисциплин приобретением навыков исследовательской работы, умения наблюдать, ставить методический эксперимент, делать из него выводы, позволяющие объективно оценивать результаты преподавания. Такие навыки необходимы для творческого подхода учителя к своей педагогической деятельности, для постоянного поиска путей её совершенствования.

Важным направлением в деятельности учителя математики, вытекающим из основных задач школьного математического образования, является постоянная забота об активизации познавательной деятельности учащихся на уроке, позволяющая обеспечить прочное и сознательное овладение системой математических знаний, умений и навыков, необходимых в повседневной жизни.

Анализ современной психолого-педагогической литературы позволяет выделить основные черты, характеризующие познавательную активность школьников:

1. Направленность внимания на объект познания и проявление интереса к нему;

2. Возникновение познавательной потребности на основе повышения ориентированной реакции к объекту познания;

3. Готовность к решению познавательной задачи, связанной с объектом познания;

4. Готовность к творческой познавательной деятельности;

5. Ряд последовательных и взаимосвязанных действий, направленных на объект познания.

Выделенные черты познавательной активности школьников дают возможность наметить основные пути в деятельности учителя математики по совершенствованию этой работы, а также установить перечень умений и навыков, необходимых для успешного осуществления этой деятельности. Так, положительное влияние на эффективность активизации познавательной деятельности учащихся на уроке математики оказывают:

1. Создание на уроке проблемной ситуации путем наиболее эффективной постановки и решения математической задачи;

2. Умелое использование приемов эмоциального воздействия на школьников, активизация их внимания;

3. Создание на уроке оптимального уровня наглядности;

4. Умение использования современных ТСО;

5. Установление на уроках математики внутри- и межпредметных связей.

Определенный вклад в описание профессии школьного учителя математики, требований, предъявляемых к его психолого-педагогической, математической и методической подготовке, вносит краткая профессиограмма учителя математики средней общеобразовательной школы, разработанная коллективом авторов РПГУ им. А.И. Герцена под руководством А.И. Щербакова [5]. Эта профессиограмма определяет объём и научнообоснованное отношение общественно-политических, специальных и психолого-педагогических знаний, а также программу формирования педагогических и методических умений и навыков, необходимых будущему учителю математики для осуществления им в процессе педагогической деятельности основных функций: информационной, развивающей, организационной, мобилизационной, конструктивной, коммуникативной, исследовательской. Разработанная Санкт-Петербургскими учеными профессиограмма учителя математики представляет теоретический и практический интерес, однако в ней не предпринималась даже попытка установления тех индивидуально-психологических особенностей учителя, которые обеспечивают ему успех в преподавании математики.

Исследованию специальных педагогических особенностей учителя математики посвящена статья А.Д. Виноградовой [6], в которой выделяются следующие способности к преподаванию математики:

1. Умение развивать творческое математическое мышление учащихся;

2. Способность развивать у учащихся «математическую зоркость» - умение соотносить математическое понятие с обобщенным его выражением в виде математической 
формулы, символа или знака;

3. «Математическое чутье» - понимание учителем уровня владения учащимися материалом специальных знаний;

4. «Математическая прозорливость» - проявляется в умении учителя разрешать изучаемые математические вопросы с точки зрения современного состояния математических знаний в доступной для учащихся форме;

5. «Математическое воображение» - умение совершать «умственный эксперимент» на математическом материале в образной форме.

И хотя в этой статье происходит постоянное смешение понятий «способность» и «умение», всё же в ней автор наиболее близок к установлению компонентов структуры специальных педагогических способностей учителя математики.

Таким образом, мы установили, что успешность педагогической деятельности учителя математики зависит:

1. Как от педагогической, так и от математической направленности при доминировании первой;

2. От развития математических способностей, которые в значительной степени детерминируют развитие педагогических способностей;

3. Слабо развитые рефлексивные педагогические способности не снижают уровня педагогической успешности при условии высокого уровня проективных педагогических способностей.

Ценность этих работ состоит в расширении теоретических представлений о структуре педагогических способностей в установлении их взаимосвязи с компонентами математических способностей учителя математики.

Таким образом, исследование деятельности учителя математики, его личностных качеств, обеспечивающих высокий профессионализм, идеи по самым разным направлениям. Приведенный обзор психолого-педагогической, методической литературы по проблеме изучения профессионально значимых качеств личности учителя математики, в частности, его способностей к преподаванию в школе математики, позволяет утверждать, что интересующие нас качества формируются и развиваются у учителя в процессе его обучения в школе, педвузе, практической работы. Те учителя, у которых математические способности гармонично сочетаются с педагогическими, достигают наиболыших высот в овладении мастерством педагога.

\section{References}

1. Gnedenko B. V. Mathematics and mathematical education in the modern world. - M: Education, 1985. - 191 pages.

2. Bradis V. M. Technique of teaching of mathematics at high school / under the editorship of A.I. Markushevich - M: 1951 . - 504 pages.

3. Kolmogorov A.N. About a profession of the mathematician. - M: Moscow State University publishing house, 1959. - 31 pages.

4. Technique of teaching of mathematics at high school: General technique / editor-in-chief Tcherkasov R. S. - M: Education, 1985. - 158 pages.

5. Short professiogramma mathematics teacher of high comprehensive school (methodical recommendations)// editor-in-chief Shcherbakov A.I. - L. : LGPI publishing house of A.I.Gertsen, 1979. - 33 pages.

6. Vinogradova A.D. Development of abilities to pedagogical activity of the mathematics teacher//the XXV Gertsenovsky readings / LGPI publishing house of A.I.Gertsen, 1972. Page 75-79. 